\title{
Transfers in a Polarized Country: Bridging the Gap between Efficiency and Stability *
}

\author{
Ori Haimanko ${ }^{\dagger} \quad$ Michel Le Breton ${ }^{\ddagger} \quad$ Shlomo Weber ${ }^{\S}$ \\ April 2003 - Revised Version.
}

\begin{abstract}
We consider a political economy model of country whose citizens have heterogeneous preferences for a national policy and some regions may contemplate a threat of secession. The country is efficient if its break-up into smaller countries leads to an aggregate utility loss. We show that in an efficient country whose citizens' preferences exhibit a high degree of polarization, a threat of secession cannot be eliminated without inter-regional transfers. We also demonstrate that, if majority voting is used to determine the redistribution schemes within the country, then a high degree of polarization yields the full compensation scheme as the unique political equilibrium.
\end{abstract}

Key Words: Transfers, Polarization, Secession, Efficiency, Stability, Political Equilibrium.

JEL Classification Numbers: H20, D70, D73.

Please send the correspondence to Shlomo Weber, Department of Economics, Southern Methodist University, Dallas TX 75275-0496, USA, e-mail: sweber@mail.smu.edu

${ }^{*}$ We wish to thank Francis Bloch, Jacques Drèze, Joan Esteban, Jean Gabszewicz, Peter Ordeshook, Joe Ostroy, Debraj Ray, Suzanne Scotchmer, Jacques Thisse, and participants of the seminars at Berkeley, Caltech, Columbia, CORE, Colorado, NYU, Queen Mary and Westfield College, Stanford, UC Irvine, UC Riverside, UCLA, University of Leuven, and the Summer School on Polarization and Conflict in San Sebastian for their useful comments. We are grateful to two anonymous referees of this journal for their valuable suggestions. We also thank Joe Tharakan for his generous research assistance.

${ }^{\dagger}$ Department of Economics, Ben-Gurion University, Beer-Sheva, Israel.

‡Université de Toulouse I, GREMAQ and IDEI, Toulouse, France.

$\S$ Department of Economics, Southern Methodist University, Dallas, U.S.A. and CORE, Catholic University of Louvain, Belgium. 


\section{Introduction}

In many cases public policies chosen through political process generate unequal benefits to groups of individuals across the country. Dissatisfaction with national policies, due to variance in benefits, compromised minority rights, inadequate promotion or preservation of distinctive local culture and language, repressive redistributive tax policies, may fuel secession sentiments in certain regions. Since a seceding region has to incur substantial per costs of laying foundations for the new country and running its administration, the breakaway tendencies are, to some extent, countered by the economies of scale generated by being a united political entity. However, even when economic efficiency unambiguously favors unity, the existence of compensation mechanisms seems to indicate that the unity cannot always be sustained without transfers to dissatisfied regions. Indeed, many federal countries have explicit transfers schemes to assist their disadvantaged regions, and even unitary countries employ this type of "solidarity mechanism" to reduce disparity across regions. ${ }^{1}$

The main objective of this paper is to examine the link between the necessity of transfer policies as secession-preventing instruments, and the distribution of citizens' characteristics arising from their heterogeneous preferences for the public policy. It is important to mention that "threats of secession" can be viewed in a more general context. Indeed, if a group of dissatisfied citizens lacks a territorial base, it may pressure the country by a threat of social conflict. Then the central government would have to consider a public policy and an appropriate transfer scheme in order to address the conflicts that in extreme cases may lead to a civil war. Thus, if the preferences of individuals are closely correlated with their geographical location, dissatisfied regions may pose a threat of secession. If the correlation between preferences and geographic location is relatively weak, and common basis for dissatisfaction is dominated by ethnic, political or economic considerations, the elimination of secession threats would amount to prevention of social instability. ${ }^{2}$

It turns out that the key determinant of whether transfers should be introduced is given by the degree of polarization of citizens' preferences. ${ }^{3}$ Polarization is a form of division in

\footnotetext{
${ }^{1}$ The examples include Russia, China, France, Italy, Belgium, Germany, Canada, Australia and many other countries. See Ter-Minassian (1997), Ahmad and Craig (1997), Le Breton and Weber (2003).

${ }^{2} \mathrm{We}$ are grateful to two referees for raising this point and suggesting alternative interpretations.

${ }^{3}$ The particular measure of polarization that we employ is due to Alesina, Baqir and Easterly (1999). This index quantifies the "median deviation" from the preferences of the median citizen.
} 
a country, whose population consists of a number of groups that are in sharp disagreement with each other and with the central government. It is also recognized that "the phenomenon of polarization is closely linked to the generation of tensions, to the possibilities of articulated rebellion and revolt" (Esteban and Ray (1994)). Since these tensions may trigger or exacerbate separatist activities, countering secession tendencies in polarized societies raises a difficult challenge for central authorities there. But is it, in fact, the case that this challenge cannot be met without transfers? And if so, are transfer policies always capable of preventing a threat of secession? Our paper gives an affirmative answer to both questions. We consider a polarized country "that is divided into groups with substantial intra-group homogeneity and inter-group heterogeneity" (Esteban and Ray (1994)). We then show that there is a critical degree of polarization, above which a break-up of a country, that should stay united on pure economic efficiency grounds, cannot be prevented without transfers, but can be avoided using them. Thus, transfer mechanisms should be used to resolve tensions and conflicts.

To describe our results we introduce two concepts, efficiency and stability of a country. The country is efficient if the aggregate benefits of unity outweigh the costs of heterogeneity of citizens' preferences over policy and any break-up of the country is inferior to its current unified structure. However, a crucial question remains of whether efficiency suffices to guarantee stability, i.e., to prevent emergence of regions prone to secession. To address this issue, we consider the case where all governments (of existing and of a new country) adopt a laissez faire approach and make no use of transfer policies, so that public decision-making is reduced to the choice of policy determined by majority voting. A region can secede when all its citizens favor secession, and the country $I$ will be called laissez faire stable if public policy determined through the mechanism of majority voting is immune against any possible threat of secession.

The main question raised in this paper is when efficient nations are (laissez faire) stable. We show that if the degree of polarization of citizens' preferences is sufficiently low, efficiency implies stability. This assertion is consistent with the conclusion of Alesina and Spolaore (1997) derived in the case of uniform distribution of citizens' preferences. In this case there is indeed a valid argument against transfers as an instrument to sustain efficiency. However, we demonstrate that if the degree of polarization is high enough, then the efficiency is 
not reconciled with the stability and there are efficient countries that are not stable. This conclusion implies that the laissez faire approach may fail to prevent secessions. Thus, in order to eliminate the gap between efficiency and stability in cases where the citizens' population is highly polarized, one should seriously contemplate introduction of transfers and our results can be viewed as an argument supporting the necessity of transfers.

Note that we impose an unanimity consent of residents of the seceding region and, moreover, no approval from the rest of the country is needed. There is a variety of alternative constitutional rules of secessions ${ }^{4}$ that impose less stringent rules for regions to secede, such as only majority approval for secession. Under these rules, the country's stability becomes more elusive and the gap between stability and efficiency is even wider. Since the purpose of our paper is to indicate the existence of the aforementioned gap in highly polarized countries, we have chosen the most restrictive secession rule to demonstrate the validity of our argument for transfer policies even in this case.

We also examine a scenario where decisions both on the national policy and on transfers are equilibrium outcomes of a political process. Following Alesina and Spolaore (1997), we assume that if a group of citizens forms its own country, both the policy and the compensation scheme are decided through majority voting. We introduce the concept of political stability to deal with this new situation: in the country, or in any region contemplating secession, the equilibrium compensation scheme can be different from laissez faire allocation. We show that if the degree of polarization is sufficiently low, then the laissez faire allocation with no transfers emerges as the only outcome of the political process. This is again in line with the Alesina and Spolaore (1997) results derived in the case of the uniform distribution. However, if the degree of polarization is sufficiently high, even the full compensation, which results in Rawlsian allocation, may emerge as the only outcome of the political process. We also demonstrate that a gap between efficiency and stability may still exist under the modified notion of stability. In particular, we show that under a high degree of polarization, an efficient country can be politically unstable. However, political stability can be restored by

\footnotetext{
${ }^{4}$ For example, even if the majority of Corsicans voted in favor of secession from France, the secession would not take place without France approving it by the national referendum. Also in Canada, the federal government would have to play a major role in approving a vote for a secession in Quebec. For a theoretical analysis of the constitutional rules of secession, see Alesina and Spolaore (1997), Bordignon and Brusco (2001), Drèze (1993), Jéhiel and Scotchmer (2001).
} 
an appropriate transfer scheme.

We now turn to the discussion on Related Literature. ${ }^{5}$ Our framework used here is that of Alesina and Spolaore (1997). Similar types of models are also employed in Casella (1992), Casella and Feinstein (1990), Dagan and Volij (2000), Feinstein (1992), Perroni and Scharf (2001), Wei (1991), Le Breton and Weber (2003), Alesina, Spolaore and Wacziarg (2000), that focus on heterogeneity of citizens' preferences. They utilize (implicitly or explicitly) the Hotelling location model in order to represent the heterogeneity of preferences among voters over the provision of public goods. Cremer, De Kerchove, and Thisse (1985) develop a model that examines the number and location of public facilities. There is also a literature including Guesnerie and Oddou (1981), (1986), Greenberg and Weber (1986), Weber and Zamir (1986), Jèhiel and Scothcmer (2001), Wooders (1978) rooted in the Tiebout tradition, where the heterogeneity of preferences among individuals and the impossibility of lump sum financing of public group provision lead to the formation of several jurisdictions. The main focus of these papers is the existence and the characterization of stable partitions of the individuals into jurisdictions, where equilibrium and stability notions capture various scenarios concerning the mobility of individuals across jurisdictions and the decision-making process to determine the level of the public good provision.

Another related group of papers focuses primarily on the heterogeneity in income rather than individuals' preferences. The first contribution to this line of research has been made by Buchanan and Faith (1987) who explore the limits that the threat of secession puts on the tax burden imposed by the majority (which can consist of rich or poor citizens). This question is the subject of Bolton and Roland (1997), who develop a model of a two-region nation with different gross income distributions. Their main focus is on the way that the threat of secession determines the choice of a purely distributive taxation rate. They assume that if secession takes place, all gross incomes are deflated by a common factor. Bolton and Roland show that fiscal accommodation in the union reduces the likelihood of secession, but by no means prevents the break-up of the nation under all circumstances. In addition, fiscal accommodation may surprisingly lead to higher taxes. As argued by Persson and Tabellini (1999), the identification of the equilibrium secession-proof tax rate is not straightforward due to the fact that individual preferences are not necessarily single-peaked.

\footnotetext{
${ }^{5}$ For survey of some of this literature see Bolton, Roland and Spolaore (1996) and Young (1998).
} 
The paper is organized as follows. In the next section we present the model and some preliminary concepts. In Section 3, we introduce the concepts of efficiency and laissez faire stability. In Section 4, we introduce the class of the distribution functions for which the bounds for efficiency and stability are derived. In Section 5 we introduce the state our result concerning the link between degree of polarization and the gap between efficiency and laissez faire stability. In Section 6 we examine the issue of voting on transfers and study the impact of polarization on the outcome of the political process. Section 7 contains some concluding remarks. The proof of most of the results is relegated to the Appendix.

\section{The Model}

We consider a nation whose citizens have preferences over a unidimensional policy space $I$, given by the interval $I=[0,1]$. We adopt a spatial interpretation of $I$, where a policy choice is represented by the location of the government. ${ }^{6}$ Each citizen's preferences are single-peaked and are identified with her ideal point in $I$. The distribution of all ideal points is given by a cumulative distribution function $F$, defined over the space $I$. For the most part, we assume that the distribution gives rise to piecewise continuous density function $f$. We denote by $\lambda(S)=\int_{S} f(t) d t$ the induced measure on subsets $S$ of $I$. The total mass of $I$ is equal to 1 , i.e., $\lambda(I)=1$.

The nation is organized either in one unified country, represented by the entire interval $I$, or it can be partitioned into several smaller countries $S_{1}, S_{2}, \ldots, S_{K}$. We do not impose restrictions on country formation, and, in principle, every group of individuals $S$ can form a country. Only for simplicity we require that each country consists of a union of a finite number of intervals with a positive mass.

Each country chooses a policy from the issue space $I$. If an individual $t$ is a citizen of country $S$, whose government chooses a location $p \in I$, then the disutility or "transportation" cost incurred by that individual, $d(t, p)$, is determined by the distance between $t$ and the location of the government:

$$
d(t, p)=|t-p|
$$

\footnotetext{
${ }^{6}$ One may consider alternative policy issues, such as tax rates, composition of public spending, policies towards ethnic minorities, etc.
} 
Each country $S$ has to cover the cost of public goods $G(S)$ which we simply call government cost. For simplicity, we assume that the government costs are independent of $S$, i.e., $G(S)=$ $g$, where $g$ is a positive constant. ${ }^{7}$

Thus, the "aggregate" cost of country $S$ is $g+D(S)$, where

$$
D(S)=\min _{p \in I} \int_{S} d(t, p) f(t) d t
$$

is the transportation cost of the citizens of $S$. It is easy to verify that the total transportation cost in the region $S$ is minimized when the government selects its median location $m$ that satisfies:

$$
\int_{S \bigcap[0, m]} f(t) d t=\int_{S \bigcap[m, 1]} f(t) d t .
$$

That is, if $M(S)$ is the set of median locations of country $S$, then for every $m \in M(S)$ we have

$$
D(S)=\int_{S} d(t, m) f(t) d t
$$

Since the transportation cost incurred by a citizen is represented by the distance between her location and the policy chosen by the country to which she belongs, it again points out to the conflict between heterogeneity and increasing returns to size. On the one hand, a larger country would require a smaller per capita contribution towards the fixed component of the government costs $g$. On the other hand, a larger and more heterogeneous country may face a larger mass of dissatisfied citizens residing far away from the capital.

We now introduce the notion of a cost allocation, that determines the monetary contribution of each individual $t$ towards the cost of government:

Definition 2.1: For every set $S \subset I$, a measurable function $x$, defined on the $S$, is called an $S$-cost allocation if it satisfies the budget constraint:

$$
\int_{S} x(t) f(t) d t=g
$$

The $I$-cost allocations will simply be referred as cost allocations.

\footnotetext{
${ }^{7}$ All our results and proofs remain virtually unchanged if the government costs assume the following functional form: $G(S)=g+\beta \lambda(S)$, where $\beta$ is a nonnegative number and $\beta \lambda(S)$ represents the variable cost component proportional to the country population size.
} 
There is a large domain of cost allocations that provide a different degree of cost burden on the citizens of the country. For our discussion below, however, the special role will be played by the laissez-faire allocation that provides no compensation from one citizen to another and simply divides the total government cost equally among all citizens of the country. That is,

Definition 2.2: The $S$-cost allocation $x_{S}^{*}$, defined by $x_{S}^{*}(t)=\frac{g}{\lambda(S)}$ for all $t \in S$, is called the laissez faire $S$-allocation. Obviously, the laissez faire $I$-allocation, or simply, the laissez faire allocation $x^{*}$ is given by $x^{*}(t)=g$ for all $t \in I$.

\section{$3 \quad$ Efficiency and Laissez Faire Stability}

The main purpose of this section is to introduce the concept of efficiency and stability. The problem of efficiency reduces to the following two questions:

- should the nation stay united or be divided into several smaller countries,

- where the governments should be located.

Our discussion in the previous section provides a simple answer to the choice of the governments' locations: if a country $S$ is formed, then its government should be located at one of its medians, and so the country incurs $D(S)$ in transportation costs. To examine the question whether the country should be united, we introduce the following condition that formally defines, when, from the perspective of a social planner, it is inefficient to break up the existing country $I$ into several smaller countries. This would imply that the aggregate transportation and monetary costs of all citizens of $I$ are minimized if the country is not partitioned into several parts. ${ }^{8}$

Definition 3.1: The country $I$ is efficient if for every partition ${ }^{9} P=\left(S_{1}, \ldots, S_{K}\right)$ of $I$ we have:

$$
D(I)+g \leq \sum_{k=1}^{K}\left[D\left(S_{k}\right)+g\right] .
$$

The following result is straightforward:

\footnotetext{
${ }^{8}$ The concept of efficiency here is a standard minimization of total loss or maximization of the sum of (linear) utilities of all citizens. As one of the referees pointed out, this notion, in general, differs from Pareto efficiency.

${ }^{9}$ The partition covers the whole country $I$ and no citizen belongs to more than one country, except, possibly, those who are located at the end points of the intervals in partition. Since these citizens represent a zero mass, we will ignore the issue of their "double" citizenship.
} 
Proposition 3.2: There is a cut-off value of government costs $g^{e}$ such that the country $I$ is efficient if and only if $g \geq g^{e}$.

This result is quite intuitive: to justify the superiority of the country $I$ on pure efficiency grounds, it has to be the case that the advantages of economies of scale are sufficient to compensate for the heterogeneity of preferences across citizens. Thus, high government costs would make it inefficient to break up a united country.

The next result formulates the Minimal Division Principle and is important for analysis of efficiency of the existing country. This principle asserts that for any distribution of citizens' ideal points the test of efficiency of country $I$ has to be verified only against its break-up into two connected countries. That is, if country $I$ is inefficient, then there exists a point $t \in I$ such that the break-up of $I$ into $[0, t]$ and $[t, 1]$ would decrease the total cost in the country $I$, i.e.,

$$
D(I)+g>D([0, t])+g+D([t, 1])+g
$$

or

$$
g<D(I)-(D([0, t])+D([t, 1]))
$$

Thus, we have

Proposition 3.3 - Minimal Division Principle: The cut-off value of government costs $g^{e}$ is given by

$$
g^{e}=S u p_{t \in I}\{D(I)-D([0, t])-D([t, 1])\}
$$

We now turn to the issue of stability. We assume that decisions on location of the government and the mechanism of financing its cost result from democratic process and are made via majority voting. The median voter theorem implies that the government of $S$ is situated at the location of its median citizen. Following Alesina and Spolaore (1997), we assume at this point that the cost allocation chosen by the government provides no compensation to any group of citizens. This is precisely the laissez faire cost allocation, according to which the burden of the government cost is shared equally across the country and each citizen in country $S$ pays a tax equal to $\frac{g}{\lambda(S)}$.

Since the focus of this section is laissez faire allocations, the notion of stability we examine here is that of laissez faire stability. The country would be stable in this regard if there is 
no region ${ }^{10} S$ such that every resident of $S$ would prefer the laissez faire allocation in $S$ over the laissez faire allocation in the united country $I$. The country $I$ is laissez faire stable if it is immune against any threat of secession. ${ }^{11}$

Definition 3.4: The region $S$ is prone to secession ${ }^{12}$ if there exists a median $m \in M(S)$ such that:

$$
d(t, m(I))+g>d(t, m)+\frac{g}{\lambda(S)} \text { for all } t \in S .
$$

The country $I$ is laissez faire stable if there is no region $S$ prone to secession. That is, there exists a median $m(I) \in M(I)$ such that for every $S$ and every $m \in M(S)$ there is $t \in S$ such that

$$
d(t, m(I))+g \leq d(t, m)+\frac{g}{\lambda(S)}
$$

The proposition below states that a country is stable if and only if economies of scale are large enough:

Proposition 3.5: There is a cut-off value of government costs $g_{l f}^{s}$ such that the country is laissez faire stable if and only if $g \geq g_{l f}^{s}$.

The next section is devoted to the calculation of the cut-off values $g^{e}$ and $g_{l f}^{s}$ for the bounds on efficiency and laissez faire stability derived in this section.

\section{Conditions for Efficiency and Laissez Faire Stability}

To determine the range of government costs that ensure efficiency and laissez faire stability we will first identify the domain of cumulative distribution functions to be used in our analysis. First, we require

SY - Symmetry: The density function $f$ is symmetric with respect to the center, i.e., $f(t)=f(1-t)$ for all $t \in I$.

\footnotetext{
${ }^{10}$ A subset $S$ of $I$ is a "region" that becomes a country after the secession takes place.

${ }^{11}$ This definition of stability is given by rule C in Alesina and Spolaore (1997).

${ }^{12} \mathrm{~A}$ model with income, rather than geographic, heterogeneity, generate different citizens' preferences over tax rates represented by the interval $I=[0,1]$. Since every citizen is characterized by her most preferred tax rate, we obtain the distribution of citizens' ideal tax rates over $I$. Obviously, in this case, one has to replace "region" by "group of citizens" and "prone to secession" by "prone to social instability".
} 
This assumption is quite standard. It implies that the geographical center $\frac{1}{2}$ of the country is also the median location in $I$.

To introduce the second assumption, we need some additional notation. For each $t \in I$, let $L_{t}$ and $R_{t}$ be the sets of citizens to the left and right of the point $t$, respectively, i.e., $L_{t}=[0, t]$ and $R_{t}=[t, 1]$. For the sets $L_{t}$ and $R_{t}$ denote by $L(t)$ and $R(t)$ their respective sets of median locations. We assume hereafter that they admit nondecreasing and continuous selections, which are differentiable except possibly in a finite number of points. In what follows, these selections will be denoted respectively $l$ and $r$ and by their derivatives by $l^{\prime}$ and $r^{\prime}$. It is useful to mention that the symmetry of the distribution guarantees that for every selection $l$ of $L$ there exists a selection ${ }^{13} r$ of $R$ such that for every $t \in I$

$$
r(t)+l(1-t)=1 .
$$

For simplicity we assume that the set $L(1)$ consists of a single point. Therefore for any selections $l$ and $r$, we will also have : $l(0)=0, l(1)=\frac{1}{2}, r(0)=\frac{1}{2}$ and $r(1)=1$. We assume:

GEM - Gradually Escalating Median: There exists a selection $l$ such that $l^{\prime}(t) \leq 1$ on the interval $[0,1]$.

We denote by $\mathcal{F}$ the set of distribution functions satisfying $S Y$ and $G E M$.

Assumption $G E M$ implies that if we increase the length of the interval $L_{t}=[0, t]$ by a small positive number $\delta$, then the median of the interval $L_{t+\delta}=[0, t+\delta]$ moves to the right by the increment smaller than $\delta$. Obviously, if the distribution is symmetric the selection $r$ of $R$, given by (3), satisfies also $r^{\prime}(t) \leq 1$.

The class of distribution functions satisfying GEM contains the family of log-concave functions. That class, in turn, includes "truncated" versions of a large number of well-known distributions, such as the uniform, the normal and the exponential, among many others. ${ }^{14}$. There are, in addition, distribution functions that are not log-concave but nevertheless satisfy the GEM assumption, such as some classes of bimodal distributions. ${ }^{15}$

\footnotetext{
${ }^{13}$ Note that if we assume $f$ to be positive everywhere, then the correspondences $L$ and $R$ are, in fact, functions and therefore the only possible selections. They are differentiable everywhere if $f$ is continuous everywhere.

${ }^{14}$ See Bagnoli and Bergstrom (1989), Caplin and Nalebuff (1991), Weber (1992) for details.

${ }^{15}$ See Le Breton and Weber (2003).
} 
We now turn to derivations of the threshold values $g^{e}$ and $g_{l f}^{s}$ defined in the preceding section.

Proposition 4.1: If the distribution $F$ belongs to the class $\mathcal{F}$, then

$$
\text { (i) } g^{e}=\frac{1}{2}-4 \int_{l\left(\frac{1}{2}\right)}^{\frac{1}{2}} t f(t) d t
$$

and

$$
\text { (ii) } g_{l f}^{s}=S u p_{0 \leq s<t \leq \frac{1}{2}} \frac{F(t)-F(s)}{1-F(t)+F(s)}\left(\frac{1}{2}-2 t+m(s, t)\right)
$$

where $m(s, t)$ denotes the median of the interval $[s, t]{ }^{16}$

The reason for computational complexity of the last formula is that, since a threat of secession should be countered for all intervals $[s, t]$, the supremum is taken over two parameters, $s$ and $t$. If, however, the threat of secession is limited to the most distant regions (intervals $[0, t]$ ), the formula for $g_{l f}^{s}$ can be substantially simplified. Formally, we say that the property of significance of distant regions - $(S D R)$ is satisfied if for any region $S$, which is prone to secession, the most distant region containing the same mass of citizens $\lambda(S)$ is also prone to secession. If SDR holds, the supremum in expression (ii) of Proposition 4.1 is attained when $s$ is equal to zero. A close inspection of the expression for $g_{l f}^{s}$ also shows that the range of parameter $t$ can be narrowed to $\left[0, t^{*}\right]$, where $t^{*}<\frac{1}{2}$ is the unique solution of the equation $\frac{1}{2}-2 t+l(t)=0$, and so individuals close to the center will never be involved in secessions. Thus,

$$
g_{l f}^{s}=S u p_{0 \leq t \leq t^{*}} \frac{F(t)}{1-F(t)}\left(\frac{1}{2}-2 t+l(t)\right) .
$$

This simplified formula cannot always be applied within the class $\mathcal{F}$. As Example A.2 in the Appendix demonstrates, a major threat of secession may emerge from regions in the center rather than from those on the margins, contrary to the SDR property. To conclude the section, we provide a sufficient condition on distribution functions to satisfy the SDR property: ${ }^{17}$

\footnotetext{
${ }^{16}$ The formula for $g_{l f}^{s}$ remains valid for the distributions that satisfy $S Y$ but not GEM. Note also that the major vehicle in derivation of $g^{e}$ and $g_{l f}^{s}$ is Proposition 3.3 that does not rely on the symmetry of the distribution. Thus, similar formulas could also be derived for continuous distributions that are not necessarily symmetric. However, since this extension would have no impact on our basic conclusions, we have chosen to limit our presentation to the symmetric case.

${ }^{17}$ This proposition generalizes the results by Alesina and Spolaore (1997) for the uniform distribution and Weber (1992) for the class of log-concave distribution functions.
} 
Proposition 4.2: SDR holds for any symmetric distribution function whose positive density $f$ satisfies $f(t) \geq 2 f(m(s, t))$ for all $s, t$ with $0 \leq s \leq t \leq \frac{1}{2}$.

\section{Polarization and Reconciliation of Efficiency and Sta- bility}

In this section we will examine the issue of reconciliation of efficiency and stability. The first question to be addressed is whether efficiency of the country $I$ would guarantee its laissez faire stability. In our framework it comes down to the comparison of the cut-off values $g^{e}$ and $g_{l f}^{s}$. If $g^{e}$ is greater than $g_{l f}^{s}$, then the efficiency of country $I$ would imply its laissez faire stability. However, if the opposite inequality holds, there is a range of government costs that yields the efficiency but not the laissez faire stability of $I$. The objective of this section is to demonstrate that there is no unambiguous answer to this question. What is even more important is that the relationship between efficiency and laissez faire stability crucially depends on the polarization of the citizens' preferences in the country $I$. We shall demonstrate that efficient countries are laissez faire stable as long as the heterogeneity of nation's citizens does not generate an excessive degree of polarization of their preferences.

To formally address the issue of polarization one would require a definition of polarization index. Esteban and Ray (1994) and Foster and Wolfson (1994) (see also Wang and Tsui (2000)) suggest general principles and offer some particular families of indices of polarization. However, since they deal with finite distributions, there is some adjustment to be made for using these indices in the continuum framework. In this paper we adopt the index of polarization, proposed by Alesina, Baqir and Easterly (1999), that represents the "median

distance to the median" ${ }^{18}$ In our framework it simply amounts to $\frac{1}{2}-l\left(\frac{1}{2}\right)$, i.e., the distance between the median of the entire distribution and the median of its left (or right) half. This index has some desirable properties and is consistent with the first degree of stochastic dominance shifts. In particular, a symmetric shift of mass of citizens away from the center towards the margins, 0 and 1, would obviously move the median of the left half of the distribution, $l\left(\frac{1}{2}\right)$, further to the left and increase the degree of polarization.

\footnotetext{
${ }^{18}$ Alternatively, one can use the polarization index proposed in Duclos, Esteban and Ray (2001) without altering results in Sections 3-5.
} 
Let $a$ be a parameter, satisfying $0<a \leq \frac{1}{3}$. For every $a$, let $F_{a}$ be the symmetric probability distribution on $[0,1]$ whose density $f_{a}$ is defined as follows:

$$
f_{a}(t)=\left\{\begin{array}{lll}
\frac{1}{3 a} & \text { if } & t \in[0, a] \cup\left[\frac{1-a}{2}, \frac{1+a}{2}\right] \cup[1-a, 1] \\
0 & \text { if } \quad t \in\left(a, \frac{1-a}{2}\right) \cup\left(\frac{1+a}{2}, 1-a\right) .
\end{array}\right.
$$

Straightforward computations lead to the following median sets of the distribution $F_{a}$ on the interval $[0, t]$ :

$$
L_{a}(t)=\left\{\begin{array}{lll}
\left\{\frac{t}{2}\right\} & \text { if } & t \in[0, a] \\
\left\{\frac{a}{2}\right\} & \text { if } t \in\left(a, \frac{1-a}{2}\right) \\
\left\{\frac{t}{2}-\frac{1}{4}+\frac{3 a}{4}\right\} & \text { if } t \in\left[\frac{1-a}{2}, \frac{1+a}{2}\right] \\
{\left[a, \frac{1-a}{2}\right]} & \text { if } t \in\left(\frac{1+a}{2}, 1-a\right) \\
\left\{\frac{t}{2}\right\} & \text { if } t \in[1-a, 1] .
\end{array}\right.
$$

The piecewise differentiable function $l_{a}(t)$ defined below represents a selection from $L_{a}(t)$ :

$$
l_{a}(t)=\left\{\begin{array}{lll}
\frac{t}{2} & \text { if } t \in[0, a] \\
\frac{a}{2} & \text { if } t \in\left(a, \frac{1-a}{2}\right) \\
\frac{t}{2}-\frac{1}{4}+\frac{3 a}{4} & \text { if } t \in\left[\frac{1-a}{2}, \frac{1+a}{2}\right] \\
t+\frac{a-1}{2} & \text { if } t \in\left(\frac{1+a}{2}, 1-a\right) \\
\frac{t}{2} & \text { if } t \in[1-a, 1] .
\end{array}\right.
$$

Since $l_{a}^{\prime}(t) \leq 1$ for all $t \in[0,1]$, it follows that for all $a \in\left(0, \frac{1}{3}\right], F_{a}$ satisfies GEM.

\section{Insert Figure 1 here}

Note that in this example, the country consists of three groups, ${ }^{19}$ located at the intervals $[0, a],\left[\frac{1-a}{2}, \frac{1+a}{2}\right]$, and $[1-a, 1]$. If $a=\frac{1}{3}$, the distribution $F_{a}$ is simply uniform on the entire interval $[0,1]$. However, if the parameter $a$ decreases, the "homogeneity" within each of three groups raises, whereas intra-group "heterogeneity gap" widens. This, according to Esteban and Ray (1994), would lead to an increased degree of polarization within the country.

Indeed, the polarization index we use, denoted by $\gamma$, yields the following expression for every distribution function $F_{a}$ :

$$
\gamma_{a}(I)=\frac{1}{2}-\frac{3 a}{4}
$$

Thus, the degree of polarization is a decreasing function of the parameter $a$, and within the class of functions $F_{a}$, the index is lowest when the distribution is uniform at $a=\frac{1}{3}$. This

\footnotetext{
${ }^{19}$ Rather than considering a two-cluster scenario, we consider here a more realistic three-cluster case that allowed us to introduce a meaningful middle region that would been absent in the two-cluster case.
} 
observation allows us to formulate our result concerning the relationship between efficiency, laissez faire stability and the degree of polarization:

Proposition 5.1: There exists a critical value $a^{*} \in\left(0, \frac{1}{3}\right)$ such that:

whenever parameter $a$ belongs to the range $\left[a^{*}, \frac{1}{3}\right]$, the value of $g^{e}$ is greater or equal to $g_{l f}^{s}$

whenever parameter $a$ belongs to the range $\left(0, a^{*}\right)$, the value of $g^{e}$ is lower than that of $g_{l f}^{s}$.

This proposition has several important implications. It states that, within a class of distribution functions satisfying assumptions $S Y$ and $G E M$, there is a critical degree of polarization below which efficiency yields laissez faire stability. ${ }^{20}$ However, if a degree of polarization is above this cut-off value, then efficiency does not imply laissez faire stability and a redistribution is needed to eliminate possible secession threats. In that respect, we reinforce the necessity of transfers as a secession preventing policy. ${ }^{21}$

In the next section we discuss the sustainability of transfer mechanisms through political institutions of the country.

\section{Voting on Transfers}

Now we turn to the study of compensation schemes that may emerge under the political mechanism of majority voting and relate it to the issue of polarization of citizens' preferences discussed in the previous section.

We assume that both decisions on the location of the government and the transfer scheme are decided by a majority voting in the country. For the sake of simplicity, let us further assume that, within each possible region $S$, only linear compensation schemes are considered and we restrict our attention to the $S$-cost allocation of the type

$$
x(t)=\mu-\alpha|t-p|,
$$

\footnotetext{
${ }^{20}$ This result generalizes Proposition 5 of Alesina and Spolaore (1997) for the uniform distribution. Even though their result is stated in terms of the size of the country, it can be also formulated in terms of government costs.

${ }^{21}$ We do not focus here on the existence and characterization of secession-preventing transfer schemes, which has been studied in Le Breton and Weber (2003). See also Haimanko, Le Breton and Weber (2003).
} 
where $p$ denotes the location of government, $\mu$ and $\alpha$ are parameters satisfying $\mu>0,0 \leq$ $\alpha \leq 1$. Under this specification, the choice of a high value of $\alpha$ corresponds to a high compensation for those located far away from $p$. In particular, $\alpha=1$ guarantees every citizen the full compensation for the disutility of distance that results in Rawlsian allocation. On the other hand, $\alpha=0$ provides no compensation at all and gives rise to laissez faire allocation. The budget balance constraint $\int_{S} x(t) f(t) d t=g$ implies that

$$
\mu(\alpha, S)=\frac{g}{\lambda(S)}+\alpha \hat{d}(S, p)
$$

where

$$
\hat{d}(S, p)=\frac{\int_{S}|t-p| f(t) d t}{\lambda(S)}
$$

is the average distance of residents of region $S$ to location $p$. Thus, considering compensation schemes, citizens of the country $S$, in effect, select a single parameter, the degree of equalization $\alpha$. This is a two-dimensional voting problem and, as in Alesina and Spolaore (1997) and Alesina, Baqir and Easterly (1999), we avoid the issue of existence of an equilibrium by assuming that the voting is sequential. The citizens first vote on the compensation scheme and then on the location of the government. A voting equilibrium will be denoted by $\left(p^{*}(S), \alpha^{*}(S)\right)$.

Note that for any choice of the policies $\alpha$ and $p$ in region $S$ within $I$, the total cost of citizen $t \in S$ is:

$$
(1-\alpha)|t-p|+\frac{g}{\lambda(S)}+\alpha \hat{d}(S, p)
$$

It will sometimes be convenient to present the cost in (4) as

$$
\alpha(\hat{d}(S, p)-|t-p|)+|t-p|+\frac{g}{\lambda(S)} .
$$

By (5), all citizens whose distance from $p$ is more than the country average $\hat{d}(S, p)$, have single peaked preferences over $\alpha$ with a peak at 1, whereas all citizens whose distance from $p$ is less than the country average, have single peaked preferences over $\alpha$ with a peak at 0 .

To state our first result concerning the voting equilibrium, we again utilize the polarization index $\gamma$ representing the median distance to the median. To simplify our discussion, let us assume that for every country $S$, its median $m(S)$ is uniquely defined. Then for every $S$ we have:

$$
\hat{d}(S, m(S))=\frac{D(S)}{\lambda(S)},
$$


where, to recall, $D(S)$ is the minimal aggregate transportation cost within $S$.

For every $S$, we define the polarization index $\gamma(S)$ representing the median distance to the median $m(S)$. That is, each of the two inequalities

$$
|t-m(S)| \leq \gamma(S) \text { and }|t-m(S)| \geq \gamma(S)
$$

holds for at least $50 \%$ of the citizens of $S$.

The next proposition characterizes the voting equilibrium in $S$. It states that the location of the government at $S$ is always chosen at its median. As far as the compensation scheme is considered, the solution is "bang-bang": if the median distance to the median, $\gamma(S)$ is smaller than the average distance from the median, $\hat{d}(S, m(S))$ the equilibrium scheme entails no compensation and, in fact, results in the laissez faire allocation; but if the median distance to the median is larger than the average distance from the median, the unique equilibrium compensation scheme entails full compensation and generates the Rawlsian allocation. Thus, countries whose degree of polarization exceeds the value $\hat{d}(S, m(S))$, sustain full compensation as the only political equilibrium.

Proposition 6.1: Assume that $\hat{d}(S, m(S)) \neq \gamma(S)$. Then there exists a unique voting equilibrium defined by:

$$
p^{*}(S)=m(S)
$$

and

$$
\alpha^{*}(S)=\left\{\begin{array}{lll}
0 & \text { if } & \hat{d}(S, m(S))>\gamma(S) \\
1 & \text { if } & \hat{d}(S, m(S))<\gamma(S)
\end{array}\right.
$$

Remark 6.2: Note also that in Proposition 6.1 we do not examine the situation when $\hat{d}(S, m(S))=\gamma(S)$. In this case we have a tie between two extreme solutions $\alpha=0$ and $\alpha=1$. (This happens, for instance, when $F$ is the uniform distribution.) In this case, one may introduce a small administrative cost of public funds that would break the tie, as in Alesina and Spolaore (1997), in favor of the laissez faire allocation.

Let us determine now the equilibrium compensation scheme for the entire nation. In the case where the function $f$ is symmetric, it is easy to verify that $\alpha^{*}(I)=1$ if and only if

$$
2 \int_{0}^{\frac{1}{2}} t f(t) d t>l\left(\frac{1}{2}\right)
$$


and the country votes for full compensation if the mean of the distribution on $\left[0, \frac{1}{2}\right]$ is greater than its median on that interval. Whether this is indeed the case, obviously depends on the type of the distribution function and, as the following two examples of the distribution functions from the class $\mathcal{F}$ indicate, the inequality (6) may or may not hold.

Example 6.3: Consider a quadratic cumulative distribution function, whose density $f(t)$ is given by

$$
f(t)= \begin{cases}4 t & \text { if } \quad t \leq \frac{1}{2} \\ 4-4 t & \text { if } \quad t \geq \frac{1}{2}\end{cases}
$$

Then $2 \int_{0}^{\frac{1}{2}} t f(t) d t=\frac{1}{3}$, whereas $l\left(\frac{1}{2}\right)=\frac{1}{\sqrt{8}}$. Thus, (6) is violated and the laissez fare allocation $\alpha^{*}(I)=0$ is the voting equilibrium.

Example 6.4: Consider the bimodal cumulative function, whose density $f(t)$ is given by

$$
f(t)= \begin{cases}\frac{4}{3}-\frac{4}{3} t & \text { if } t \leq \frac{1}{2} \\ \frac{4}{3} t & \text { if } t \geq \frac{1}{2}\end{cases}
$$

Then $2 \int_{0}^{\frac{1}{2}} t f(t) d t=\frac{2}{9}$ whereas $l\left(\frac{1}{2}\right)=\frac{4-\sqrt{10}}{4} \approx 0.21$. Thus, (6) holds and therefore the full compensation scheme $\alpha^{*}(I)=1$ emerges as the only political equilibrium.

Since the equilibrium notion in this section is different from that in Section 3, the definition and analysis of stability there should be modified. Indeed, it should take into account the compensation schemes $\alpha^{*}(I)$ in the country $I$ and $\alpha^{*}(S)$ for any country $S$ that contemplates a threat of secession.

Definition 6.5: The region $S$ is p-prone to secession if, given voting equilibria in $I$ and $S$, all citizens of $S$ would be better off if $S$ secedes, i.e., the following inequality

$$
\left(1-\alpha^{*}(S)\right)|t-m(S)|+\frac{g+\alpha^{*}(S) D(S)}{\lambda(S)}<\left(1-\alpha^{*}(I)\right)|t-m(I)|+g+\alpha^{*}(I) D(I) .
$$

holds for all $t \in S$. The country $I$ is politically stable if there is no region $p$-prone to secession.

We immediately observe:

Proposition 6.6: Assume that $D(I) \neq \gamma(I)$. Then there is a cut-off value of the government costs, denoted $g^{p}$, such that the country is politically stable if and only if $g \geq g^{p}$. 
It is natural to study a link between efficiency and political stability. The following example exhibits a country that is efficient but is politically unstable.

Example 6.7: Consider the following symmetric distribution on $[0,1]$ :

region $S_{1}-\frac{3}{10}$ of the total population located in 0 ,

region $S_{2}-\frac{4}{10}$ of the total population located in $\frac{1}{2}$,

region $S_{3}-\frac{3}{10}$ of the total population located in 1 .

Proposition 4.1 yields $g^{e}=\frac{3}{20}$. Turn now to the issue of secession. For the country $I$, $m(I)=\frac{1}{2}$ and since $\gamma(I)=\frac{1}{2}$ and $D(I)=\int_{I}|t-m(I)| f(t) d t=\frac{3}{10}$, we have $\alpha^{*}(I)=1$.

For three regions $S_{1}, S_{2}$, and $S_{3}$, the choice of $\alpha$ is irrelevant since there would be no transportation costs in the case of their secession. For regions $S_{1} \cup S_{2}$ and $S_{2} \cup S_{3}$, the median is located at $\frac{1}{2}$ and, obviously, $\alpha^{*}(S)=0$. For region $S_{1} \cup S_{3}, \alpha^{*}$ is equal to zero and the average distance to the median is $\frac{1}{2}$. Then country $I$ is politically stable if the following four inequalities holds:

$$
\begin{gathered}
g+\frac{3}{10} \leq \frac{10 g}{3}\left(\text { for regions } S_{1} \text { or } S_{3}\right), \\
g+\frac{3}{10} \leq \frac{10 g}{4}\left(\text { for region } S_{2}\right), \\
g+\frac{3}{10} \leq \frac{10 g}{7}+\frac{1}{2}\left(\text { for regions } S_{1} \bigcup S_{2} \text { or } S_{2} \bigcup S_{3}\right), \\
g+\frac{3}{10} \leq \frac{10 g}{6}+\frac{1}{2}\left(\text { for region } S_{1} \bigcup S_{3}\right) .
\end{gathered}
$$

These inequalities are satisfied if $g \geq g^{p}=\frac{1}{5}$. Since $g^{p}>g^{e}$, it follows that the country $I$ can be efficient without being politically stable.

It is instructive to point out that in this example a threat of secession comes from the center $S_{2}$. Indeed, if joined by the central region $S_{2}$, the more distant regions $S_{1}$ or $S_{3}$ would have sufficient number of citizens to enforce full equalization through the voting mechanism.

We will show now that efficiency can be restored through the transfer mechanism. Consider a symmetric cost allocation that assigns the total cost $x$ to every citizen in regions $S_{1}$ and $S_{3}$ and $y$ to every citizen in region $S_{2}$. To be immune to the threat of secession, it has to satisfy the following list of inequalities:

$$
\begin{gathered}
x+\frac{2 y}{3}=\frac{10 g}{6}+\frac{1}{2} \text { (budget constraint), } \\
\left.x \leq \frac{10 g}{3} \text { (secession threat of regions } S_{1} \text { or } S_{3}\right),
\end{gathered}
$$




$$
\begin{gathered}
y \leq \frac{10 g}{4}\left(\text { secession threat of region } S_{2}\right), \\
x+\frac{4 y}{3} \leq \frac{10 g}{3}+\frac{1}{2}\left(\text { secession threat of regions } S_{1} \bigcup S_{2} \text { or } S_{2} \bigcup S_{3}\right), \\
x \leq \frac{10 g}{6}+\frac{1}{2}\left(\text { secession threat of region } S_{1} \bigcup S_{3}\right)
\end{gathered}
$$

From the first and the last inequalities we obtain $y \geq 0$. That is, the citizens in $S_{2}$ must make a nonnegative contribution. Since $x=\frac{10 g}{6}+\frac{1}{2}-\frac{2 y}{3}$. the three intermediate inequalities yield

$$
\operatorname{Max}\left(0, \frac{3}{4}-\frac{5 g}{2}\right) \leq y \leq \frac{5 g}{2}
$$

(See Figure 2).

\section{Insert Figure 2 here}

We can see that a solution to (7) exists if and only if $g$ is greater or equal to the value $\frac{3}{20}=g^{e}$, the point where the two lines intersect. This demonstrates that we can restore efficiency by using transfers. Figure 2 identifies the values of $y$ that allow prevention of secession threats. It is interesting to note that moderate effects of economies of scale ( $g$ is close to $g^{e}$ ) yield a narrow range of secession-proof compensation schemes.

\section{Concluding Remarks}

This paper considers a model of a country with heterogeneous population where the diversity may arise from differences in geographical locations or different preferences for public policies chosen by the central government. Since some groups of individuals (regions) could be dissatisfied with those policies, they may pose a threat of secession. We then turn to redistribution policies of the central government targeting dissatisfied regions and address the question whether transfer policies are necessary to prevent threats of secession. It turns out that the key determinant of whether transfers should be introduced is given by the degree of polarization of citizens' preferences. Since a polarized society consists of a number of distinct groups that are in sharp disagreement over the policies of the central government, a high degree of polarization may necessitate an introduction of redistribution policies by the central authorities. We show that this is indeed the case even in efficient countries, i.e., those that should be kept united on pure economic efficiency grounds. Specifically, we 
demontstrate that there is a critical degree of polarization, above which a break-up of an efficient country cannot be prevented without transfers, but can be avoided using them. This result reinforces the importance of transfer mechanisms and makes a stronger case for transfers in highly polarized societies. ${ }^{22}$

We also examine a scenario where decisions both on the national policy and on transfers are equilibrium outcomes of a political process, where both the policy and the compensation scheme are decided through majority voting. We show, in particular, that if the degree of polarization is sufficiently high, then extreme type of transfers that equalizes utilities of all citizens and results in Rawlsian allocation will emerge as the only outcome of the political process.

The model presented in this paper can be extended in several directions. The major step that should be undertaken is to provide a multidimensional framework that would capture the fact that individuals differ on the basis of their wealth, ethnicity, culture, religion, preferences for public policy and geographical location. This type of model would allow to address an important theoretical and empirical analysis of economic transfers in societies that are characterized by a high degree of ethnic, cultural, religious and linguistic diversity.

Another interesting direction is an extension of the model to a multi-period framework. Indeed, appropriate transfer policies at one period may impact a degree of polarization and disparity and, hence, alter the nature of regional secession threats in the next period. This important and relevant investigation is left to future research.

\section{Appendix}

Proof of Proposition 3.3: First observe that the definition of efficiency implies that we can restrict our attention to intervals only. Indeed, we always can reduce the total transportation cost in a partition consisting of disconnected regions by rearranging them into connected ones. Moreover, by (1), for every $t \in I$, we have

$$
g^{e} \geq \operatorname{Sup}_{t \in I}(D(I)-D([0, t])-D([t, 1])) .
$$

\footnotetext{
${ }^{22}$ This paper deals with the theoretical foundations for redistributive polices of the central government. For an overview of the "real world" transfer policies in countries with various degrees of polarization and regional disparities, see Le Breton and Weber (2003).
} 
Denote

$$
\Phi(t, s)=D([0, t])-D([0, s])-D([s, t])
$$

for all $s, t \in I$ with $s \leq t$ and

$$
\Psi(t)=S u p_{s \in[0, t]} D([0, t])-D([0, s])-D([s, t])
$$

for all $t \in I$. The supremum in (8) is attained at a median of the interval $[0, t]$.

For almost every point $t$, at which the function $f$ is continuous and positive, both $l(t)=$ $m(0, t)$ and $m(l(t), t)$ are determined uniquely. Thus, the envelope theorem implies that

$$
\Psi^{\prime}(t)=[m(l(t), t)-l(t)] f(t)>0
$$

If $t$ is such that $f$ is equal to zero in its neighborhood, then $\Psi^{\prime}(t)=0$. The set of points for which none of these two properties holds has the Lebesgue measure zero. Therefore $\Psi^{\prime}(t) \geq 0$ for almost all $t \in I$, and hence $\Psi$ is a non-decreasing function.

Now take any $t \in I$ and any partition $\left\{\left[s_{0}, s_{1}\right),\left[s_{1}, s_{2}\right), \ldots,\left[s_{k-1}, s_{k}\right]\right\}$ of $[0, t]$ into $k$ consecutive intervals with $s_{0}=0$ and $s_{k}=t$. We will prove by induction on $k$ that $g \geq \Psi(1)$ implies:

$$
D([0, t])+g \leq \sum_{i=1}^{k}\left(D\left(\left[s_{i-1}, s_{i}\right]\right)+g\right),
$$

or, equivalently,

$$
(k-1) g \geq D([0, t])-\sum_{i=1}^{k}\left(D\left(\left[s_{i-1}, s_{i}\right]\right) .\right.
$$

The monotonicity of $\Psi$ implies that $\Psi(t)<\Psi(1)$, and so the claim is true for $k=2$. Let

$$
\begin{gathered}
D([0, t])-\sum_{i=1}^{k}\left(D\left(\left[s_{i-1}, s_{i}\right]\right)=\right. \\
{\left[D([0, t])-D\left(\left[0, s_{k-1}\right]\right)-D\left(\left[s_{k-1}, t\right]\right)\right]+\left[D\left(\left[0, s_{k-1}\right]\right)-\sum_{i=1}^{k-1}\left(D\left(\left[s_{i-1}, s_{i}\right]\right)\right]\right.}
\end{gathered}
$$

Invoking the monotonicity of $\Psi$ again, we conclude that the first term on the right hand side is smaller than $g$, and, by the induction hypothesis, the second term on the right hand side is smaller than $(k-2) g$. Thus, inequality (9) follows. The general claim of the proposition follows by applying the above inequality for $t=1$. 
We will use the following lemma, which allows us to restrict our analysis of possible threats of secession to intervals whose endpoints are located on the same side of the median $m(I):$

Lemma A.1: If a region $S$ is prone to secession, then either $S \subset[0, m(I)]$ or $S \subset[m(I), 1]$. Moreover, there exists an interval $T$ prone to secession such that $\lambda(T)=\lambda(S)$.

Proof: Let $S$ be a region prone to secession and assume, without loss of generality, that $m \in m(S)$ satisfies $m \leq m(I)$. Then $t \in S \cap[m(I), 1]$ would imply $\frac{g}{\lambda(S)}+(t-m) \geq$ $g+(t-m(I))$, contradicting our assumption of $S$ being prone to secession.

Now let $S \subset[0, m(I)]$ be a region prone to secession when government of $S$ choosing its location at $m \in m(S)$. Let now $T=T_{1} \cup T_{2}$ with $T_{1}=[a, m], T_{2}=[m, b]$, and $\lambda\left(T_{1}\right)=\lambda\left(T_{2}\right)=\frac{\lambda(S)}{2}$. Since, by construction, $m \in m(T), \lambda(T)=\lambda(S)$, and $b \leq S u p_{t \in S} t$, we conclude that $T$ is prone to secession

Proof of Proposition 3.5: The definition of laissez faire stability implies that if $I$ is laissez faire stable for some $g$, it is also the case for any $g^{\prime} \geq g$. Thus, it suffice to show that there exists a value of $g$ for which $I$ is laissez faire stable.

Assume that for some value of $g$, a region $S$ is prone to secession. Inequality (2) can be rewritten as

$$
d(t, m(I))-d(t, m)>g\left(\frac{1}{\lambda(S)}-1\right)
$$

Lemma A.1 implies that either $S \subset[0, m(I)]$ or $S \subset[m(I), 1]$. Since $S$ is located on one side of the median $m(I)$, we have $d(t, m(I))-d(t, m) \leq \operatorname{Max}(m(I), 1-m(I)) \leq 1$ for all $m \in M(S)$ and all $t \in S$.

However, since $\lambda(S) \leq \frac{1}{2}$, it follows that if $g \geq 1$, the inequality (10) is violated for $S$. Thus, for $g \geq 1$ no region is prone to secession and $I$ is laissez faire stable.

Proof of Proposition 4.1: (i) Proposition 3.3 implies that $g^{e}=\Psi(1)$, where $\Psi$ was defined by (8). Since $f$ is symmetric, we have:

$$
\Psi(1)=2 \int_{0}^{\frac{1}{2}}\left(\frac{1}{2}-t\right) f(t) d t-I n f_{t \in I} \Gamma(t)
$$


where

$$
\begin{aligned}
\Gamma(t)= & \int_{0}^{l(t)}(l(t)-s) f(s) d s+\int_{l(t)}^{t}(s-l(t)) f(s) d s \\
& +\int_{t}^{r(t)}(r(t)-s) f(s) d s+\int_{r(t)}^{1}(s-r(t)) f(s) d s .
\end{aligned}
$$

Simple calculations show that at almost every point $t$ at which $f$ is continuous and positive,

$$
\Gamma^{\prime}(t)=(2 t-l(t)-r(t)) f(t) .
$$

If $t$ is such that $f$ is equal to zero in its neighborhood, then clearly $\Gamma^{\prime}(t)=0$. Since $F$ satisfies assumptions $S Y$ and $G E M$, it follows that $l^{\prime}(t) \leq 1$, and, by $(3), r^{\prime}(t) \leq 1$. Thus $(2 t-l(t)-r(t))$ is non-decreasing and is equal to zero at $\frac{1}{2}$. This implies that $\Gamma^{\prime}(t)$ is nonpositive almost everywhere on the interval $\left[0, \frac{1}{2}\right]$ and is non-negative almost everywhere on the interval $\left[\frac{1}{2}, 1\right]$. Therefore $\Gamma$ attains its minimum at the point $\frac{1}{2}$.

As a result,

$$
\Psi(1)=2\left[\int_{0}^{\frac{1}{2}}\left(\frac{1}{2}-t\right) f(t) d t-\int_{0}^{l\left(\frac{1}{2}\right)}\left(l\left(\frac{1}{2}\right)-t\right) f(t) d t-\int_{l\left(\frac{1}{2}\right)}^{\frac{1}{2}}\left(t-l\left(\frac{1}{2}\right)\right) f(t) d t\right],
$$

that can be simplified to

$$
\Psi(1)=\frac{1}{2}-4 \int_{l\left(\frac{1}{2}\right)}^{\frac{1}{2}} t f(t) d t .
$$

(ii) By Lemma A.1 and the symmetry of $f$, we may consider a threat of secession only by intervals $[s, t]$ with $0 \leq s<t \leq \frac{1}{2}$. Take any pair $s, t \in\left[0, \frac{1}{2}\right]$ with $s<t$. The region $S=[s, t]$ with a positive mass is not prone to secession if and only if the citizen $t$ is better off in the unified country than in the region $[s, t]$, with capital at its rightmost median $m(s, t)$. That is,

$$
g+\left(\frac{1}{2}-t\right) \leq \frac{g}{F(t)-F(s)}+(t-m(s, t))
$$

or

$$
g \geq \frac{F(t)-F(s)}{1-F(t)+F(s)}\left(\frac{1}{2}-2 t+m(s, t)\right) .
$$

Thus,

$$
g_{l f}^{s}=\operatorname{Sup}_{0 \leq s<t \leq \frac{1}{2}} \frac{F(t)-F(s)}{1-F(t)+F(s)}\left(\frac{1}{2}-2 t+m(s, t)\right) .
$$


Proof of Proposition 4.2: Since $f$ is symmetric, it suffices to consider regions $S=[s, t]$ with $0 \leq s<t \leq \frac{1}{2}$, and, since $f>0, m(s, t)$ is uniquely defined. We want to prove that if $S$ is prone to secession, then the region $T=[0, c]$ with $\lambda(T)=\lambda(S)$ is also prone to secession. To this end, fix any $t$ in $\left(0, \frac{1}{2}\right)$ and consider all intervals $[s, b(s)] \subset\left[0, \frac{1}{2}\right]$ such that $\lambda([s, b(s)])=t$, or, equivalently, $F(b(s))-F(s)=t$.

Since $F$ is differentiable, implicit derivation yields:

$$
b^{\prime}(s)=\frac{f(s)}{f(b(s))} .
$$

By definition, $q(s) \equiv m(s, b(s))$ is the unique solution of the equation

$$
F(q(s))=\frac{F(s)+F(b(s))}{2},
$$

and so, after implicit derivation and the use of (11),

$$
g^{\prime}(s)=\frac{f(s)}{f(q(s))} .
$$

Now suppose that $[s, b(s)]$ is prone to secession. Take $\epsilon>0$ small enough and move $s$ to the left by $\epsilon$, while maintaining the measure of the interval, i.e., consider $[s-\epsilon, b(s-\epsilon)]$. Since $[s, b(s)]$ is prone to secession,

$$
g \frac{1-t}{t}<\frac{1}{2}-2 b(s)+q(s) .
$$

To prove that $[s-\epsilon, b(s-\epsilon)]$ is also prone to secession, it suffices to show that $b(s-\epsilon)$ finds it profitable to secede, i.e.,

$$
g \frac{1-t}{t}<\frac{1}{2}-2 b(s-\epsilon)+g(s-\epsilon)
$$

But

$$
\left[\frac{1}{2}-2 b(s-\epsilon)+g(s-\epsilon)\right]-\left[\frac{1}{2}-2 b(s)+q(s)\right]=\epsilon\left[2 b^{\prime}(s)-q^{\prime}(s)\right]+O\left(\epsilon^{2}\right)
$$

Therefore, it is enough to prove that:

$$
2 b^{\prime}(s)-q^{\prime}(s) \geq 0,
$$

or, using (11) and (12), that

$$
f(b(s)) \leq 2 f(q(s)) .
$$


Since $q(s)=m(s, b(s))$, this last inequality follows from our assumption on $f$.

Example A.2 - Threat of Secession from the Center: Let $x, y$ be positive numbers with $x<y<\frac{1}{2}$. Consider the following ${ }^{23}$ distribution, which, obviously, is not log-concave: region $S_{1}-12 \%$ of the population is in 0 , region $S_{2}-12 \%$ of the population is in $x$, region $S_{3}-20 \%$ of the population is in $y$, region $S_{4}-12 \%$ of the population is in $\frac{1}{2}$, region $S_{5}-20 \%$ of the population is in $\frac{1}{2}-y$, region $S_{6}-12 \%$ of the population is in $\frac{1}{2}-x$, region $S_{7}-12 \%$ of the population is in 1 .

If we consider only the intervals with the endpoint at 0 , the cut-off value of $g$ is the lowest value of $g$ for which the regions $S_{1}, S_{1} \cup S_{2}$ and $S_{1} \cup S_{2} \cup S_{3}$ are not prone to secession. Thus, the following three inequalities hold:

$$
\frac{100}{12} g \geq g+\frac{1}{2}, \quad \frac{100}{24} g \geq g+\frac{1}{2}-x, \frac{100}{44} g+y-x \geq g+\frac{1}{2}-y .
$$

After rearranging the terms, we obtain

$$
g \geq \operatorname{Max}\left(\frac{3}{44}, \frac{3}{19}-\frac{6}{19} x, \frac{11}{28}-\frac{22}{28}(2 y-x)\right) .
$$

On the other hand, the region consisting of $S_{2}$ and $S_{3}$ is not prone to secession if

$$
g \geq \frac{4}{17}-\frac{8}{17} y
$$

Now choose $g=0.157$ and $y=0.164$. Then inequality (14) is violated. However, it is easy to verify that inequality (13) is strict as long as $0.003<x<0.027$. Thus, for these parameter values, the region $S_{2} \cup S_{3}$ is prone to secession whereas the regions containing $S_{1}$ are not.

The intuition here is clear. The individuals located in 0 wish to join prone to secession region $S_{2} \cup S_{3}$. However, they cannot commit, once in, to maintain the location of the seceding government at $y$. Instead, by joining in, the region $S_{1}$ would shift the median of the new region from $y$ to $x$. This shift, however, is going to be rejected by the region $S_{3}$ that would be unwilling to join the secession.

\footnotetext{
${ }^{23}$ The distribution here contains "atoms". It can be approximated by distributions with a positive density displaying the same features but the required algebra would be too tedious to present it here.
} 
Proof of Proposition 5.1: Let us compare the values of $g^{s}$ and $g^{e}$. First, we calculate $g^{e}$. By (i) of Proposition 4.1,

$$
g^{e}=\frac{1}{2}-4 \int_{l_{a}\left(\frac{1}{2}\right)}^{\frac{1}{2}} t f(t) d t
$$

Since $l_{a}\left(\frac{1}{2}\right)=\frac{3 a}{4}$, we have

$$
g^{e}=\frac{1}{6}-\frac{a}{8}
$$

Now turn to $g_{l f}^{s}$. It is easy to see that the SDR property holds. Moreover, $\frac{1}{2}-2 t+l(t) \leq 0$ whenever $t \geq \frac{1-a}{2}$. Furthermore, note that $l_{a}(t)$ is constant on the interval $\left(a, \frac{1-a}{2}\right)$. Thus, by (ii) of Proposition 4.1,

$$
g_{l f}^{s}=S u p_{t \in[0, a]} \frac{F(t)}{1-F(t)}\left(\frac{1}{2}-2 t+l(t)\right)
$$

or

$$
g_{l f}^{s}=\operatorname{Max}_{t \in[0, a]} \frac{\frac{t}{3 a}}{1-\frac{t}{3 a}}\left(\frac{1}{2}-2 t+\frac{t}{2}\right)=\operatorname{Max}_{t \in[0, a]} \frac{t-3 t^{2}}{2(3 a-t)} .
$$

Note that the maximum of the last expression, $t^{m}$, is given by

$$
t^{m}= \begin{cases}a & \text { if } \quad 0<a \leq \frac{1}{5} \\ 3 a-\sqrt{9 a^{2}-a} & \text { if } \quad \frac{1}{5} \leq a \leq \frac{1}{3} .\end{cases}
$$

By substituting the expression for $t^{m}$ to derive $g_{l f}^{s}$, we obtain

$$
g_{l f}^{s}=\left\{\begin{array}{lll}
\frac{1}{4}-\frac{3 a}{4} & \text { if } \quad 0<a \leq \frac{1}{5} \\
9 a-3 \sqrt{9 a^{2}-a}-\frac{1}{2} & \text { if } \quad \frac{1}{5} \leq a \leq \frac{1}{3} .
\end{array}\right.
$$

\section{Insert Figure 3 here}

Thus, the functional expression for $g_{l f}^{s}$ consists of two parts, linear and non-linear in $a$. By comparing the values of $g^{e}$ and $g_{l f}^{s}$, it remains to observe that only the linear part of $g_{l f}^{s}$ intersects the curve for $g^{e}$ and that the intersection occurs at $a^{*}=\frac{2}{15}$ (see Figure 3). Thus, $g^{s}>g^{e}$ for $a<\frac{2}{15}$, whereas $g^{s}<g^{e}$ for $a>\frac{2}{15}$.

Proof of Proposition 6.1: Suppose that the value of $\alpha$ has been determined in the first stage of voting and let us examine the second stage where the government location $p$ is selected. If $\alpha$ has been chosen equal to 1 , then, by (4), the preferences of all citizens over locations in $I$ are identical and every $t$ would choose $m(S)$ to minimize the average transportation cost. Let $\alpha<1$. By (4), the total cost of a citizen $t \in S$ consists of 
two variable components: her own transportation cost, $(1-\alpha)|t-p|$, and the average transportation cost in $S, \hat{d}(S, p)$. In terms of her own transportation cost, the preferences of individual $t$ over locations are single peaked, with $t$ being her ideal point. Since all citizens wish to minimize the average transportation cost, the median voter theorem immediately implies that the only second-stage equilibrium is the median location $p^{*}=m(S)$.

Now let us turn to the first stage. Since $p^{*}(S)=m(S)$, it follows that if $\gamma(S)$ is less than the average distance to $m(S)$ within $S$, then, by (5), the majority of the citizens in $S$ will support $\alpha=0$, whereas if $\gamma(S)$ is greater than the average distance to $m(S)$ within $S$, then the majority of the citizens in $S$ will support $\alpha=1$.

Proof of Proposition 6.6: Note that, by (4), the condition for a region $S$ to be $p$-prone to secession can be rewritten as

$$
\frac{g+\alpha^{*}(S) D(S)}{\lambda(S)}+\left(1-\alpha^{*}(S)\right)|t-m(S)|<g+\alpha^{*}(I) D(I)+\left(1-\alpha^{*}(I)\right)|t-m(I)| .
$$

Since $\lambda(S) \geq 1$, it immediately implies that if region $S$ is not $p$-prone to secession when the value of government cost is $g$, it is also not $p$-prone to secession for all values of $g^{\prime}$ greater that $g$. Thus, it remains to show that there exists a sufficiently large value of $g$ for which the country $I$ is politically stable.

Take now any positive number $\epsilon<1$. The above inequality implies that if a region $S$ with $\lambda(S)<1-\epsilon$ is $p$-prone to secession then

$$
g<\frac{\lambda(S)}{1-\lambda(S)}<\frac{1-\epsilon}{\epsilon} .
$$

Thus, by setting $g \geq \frac{1-\epsilon}{\epsilon}$ we eliminate a threat of secession by "small" regions that allows us to focus on those with $\lambda(S) \geq 1-\epsilon$.

Consider first the case where $\alpha^{*}(I)=0$ and let $\epsilon$ be chosen in such a way that $\alpha^{*}(S)=0$ for all $S$ with $\lambda(S) \geq 1-\epsilon$. Since no compensation takes place, the value of the government costs $g_{l f}^{s}$ would prevent a threat of secession.

Finally, let $\alpha^{*}(I)=1$. Again, choose $\epsilon>0$ such that for any $S$ with $\lambda(S)>1-\epsilon$ would have $\alpha^{*}(S)=1$. $S$ will be $p$-prone to secession if

$$
\frac{g+D(S)}{\lambda(S)}<g+D(I)
$$


or

$$
\left.g<\frac{\lambda(S)}{1-\lambda(S)}(D(I))-\frac{D(S)}{\lambda(S)}\right)
$$

Since $D(I) \leq \int_{I}|t-m(S)| f(t) d t$, it follows $S$ will be $p$-prone to secession only if

$$
g<\frac{\lambda(S)}{1-\lambda(S)} \int_{I \backslash S}|t-m(S)| f(t) d t \leq \lambda(S) \leq 1
$$

To complete the proof, it suffices to observe that the cut-off value $g^{p}$ can be chosen as the largest number among the three: $1, \frac{1-\epsilon}{\epsilon}$ and $g_{l f}^{s} . \square$

\section{References}

Ahmad, E. and J. Craig (1997) "Intergovernmental Transfers", in Fiscal Federalism in Theory and Practice, T. Ter-Minassian, ed., International Monetary Fund, Washington D.C.

Alesina, A. and E. Spolaore (1997) "On the Number and Size of Nations", Quarterly Journal of Economics 113, 1027-1056.

Alesina, A., Baqir, R. and W. Easterly (1999) "Public Goods and Ethnic Divisions", Quarterly Journal of Economics, 114, 1243-1284.

Alesina, A., Spolaore, E. and R. Wacziarg (2000) "Economic Integration and Political Disintegration", American Economic Review, 90, 1276-1296.

Bagnoli, M. and T. Bergstrom (1989) "Log-Concave Probability and its Applications", University of Michigan Discussion Paper.

Bolton, P. , Roland, G. and E. Spolaore (1996) "Economic Theories of the Breakup and Integration of Nations", European Economic Review 40, 697-706.

Bolton, P. and G. Roland (1997) "The Break-Up of Nations: A Political Economy Analysis", Quarterly Journal of Economics 113, 1057-1090.

Bordignon, M. and S. Brusco (2001) "Optimal Secession Rules", Discussion paper, European Economic Review 45, 1811-1834.

Buchanan, J.M. and R.I. Faith (1987) "Secessions and the Limits of Taxation: Toward a Theory of Internal Exit", American Economic Review 77, 1023-31.

Caplin, A. and B. Nalebuff (1991) "Aggregation and Social Choice: A Mean Voter Theorem", Econometrica 59, 1-24. 
Casella, A. (1992) "On Markets and Clubs: Economic and Political Integration of Regions with Unequal Productivity", American Economic Review, Papers and Proceedings 82, 115121.

Casella, A. and J. Feinstein (1990) "Public Goods in Trade: On the Formation of Markets and Political Jurisdictions", NBER, Working Paper \# 3554.

Cremer, H., De Kerchove, A.M. and J. Thisse (1985) "An Economic Theory of Public Facilities in Space", Mathematical Social Sciences 9, 249-262.

Dagan, N. and O. Volij (2000) "Formation of Nations in a Welfare-State Minded World", Journal of Public Economic Theory, 2, 157-181.

Drèze, J. (1993) "Regions of Europe : A Feasible Status, to be Discussed", Economic Policy, 17, 265-307.

Duclos, J., Esteban, J.M. and D. Ray (2001) "Polarization Measures for Continuous Distributions", Discussion Paper.

Esteban, J.M. and D. Ray (1994) "On the Measurement of Polarization", Econometrica, 819-851.

Feinstein, J. (1992) "Public Good Provision and Political Stability in Europe", American Economic Review, Papers and Proceedings 82, 323-329.

Foster, J.E. and M.C. Wolfson (1994) "Polarization and the Decline of the Middle Class: Canada and the U.S.", Mimeo.

Greenberg, J. and S. Weber (1986) "Strong Tiebout Equilibrium Under Restricted Preferences Domain", Journal of Economic Theory 38, 101-117.

Guesnerie, R. and C. Oddou (1981) "Second Best Taxation as a Game", Journal of Economic Theory 25, 67-91.

Guesnerie, R. and C. Oddou (1987) "Increasing Returns to Size and their Limits", Scandinavian Journal of Economics, 90, 259-273.

Haimanko, O., Le Breton, M. and S. Weber (2003), "Voluntary Formation of Communities for Provision of Public Projects", Journal of Economic Theory, forthcoming.

Jéhiel, P. and S. Scotchmer (2001) "Constitutional Rules of Exclusion in Jurisdiction Formation", Review of Economic Studies 68, 393-411.

Le Breton, M and S. Weber (2003), "The Art of Making Everybody Happy: How to Prevent a Secession", IMF Staff Papers, forthcoming. 
Perroni, C. and K. Scharf (2001) "Tiebout with Politics : Capital Tax Competition and Constitutional Choices", Review of Economic Studies 68, 133-154.

Persson, T. and G. Tabellini (1999) "Political Economics and Public Finance", Mimeo, Bocconi University.

International Monetary Fund (1997) Fiscal Federalism in Theory and Practice, T. TerMinassian, ed., Fiscal Affairs Department, Washington D.C.

Wang, Y.Q. and K.Y. Tsui (2000) "Polarization Orderings and New Classes of Polarization Indices", Journal of Public Economic Theory, 2, 349-363.

Weber, S. (1992) "On Hierarchical Spatial Competition", Review of Economic Studies $59,407-425$.

Weber, S. and S. Zamir (1985) "Proportional Taxation: Nonexistence of Stable Structures in an Economy with Public Good", Journal of Economic Theory 35, 178-185.

Wei, S.J. (1991) "To Divide or to Unite: A Theory of Secessions", Mimeo, University of California at Berkeley.

Wooders, M.H. (1978) "Equilibria, the Core and Jurisdiction Structures in Economies with a Local Public Good", Journal of Economic Theory, 18, 328-348.

Young, R. (1998) "Secession Games", in Palgrave Dictionary of Economics and the Law, P. Newman, eds., Stockton Press, New York. 


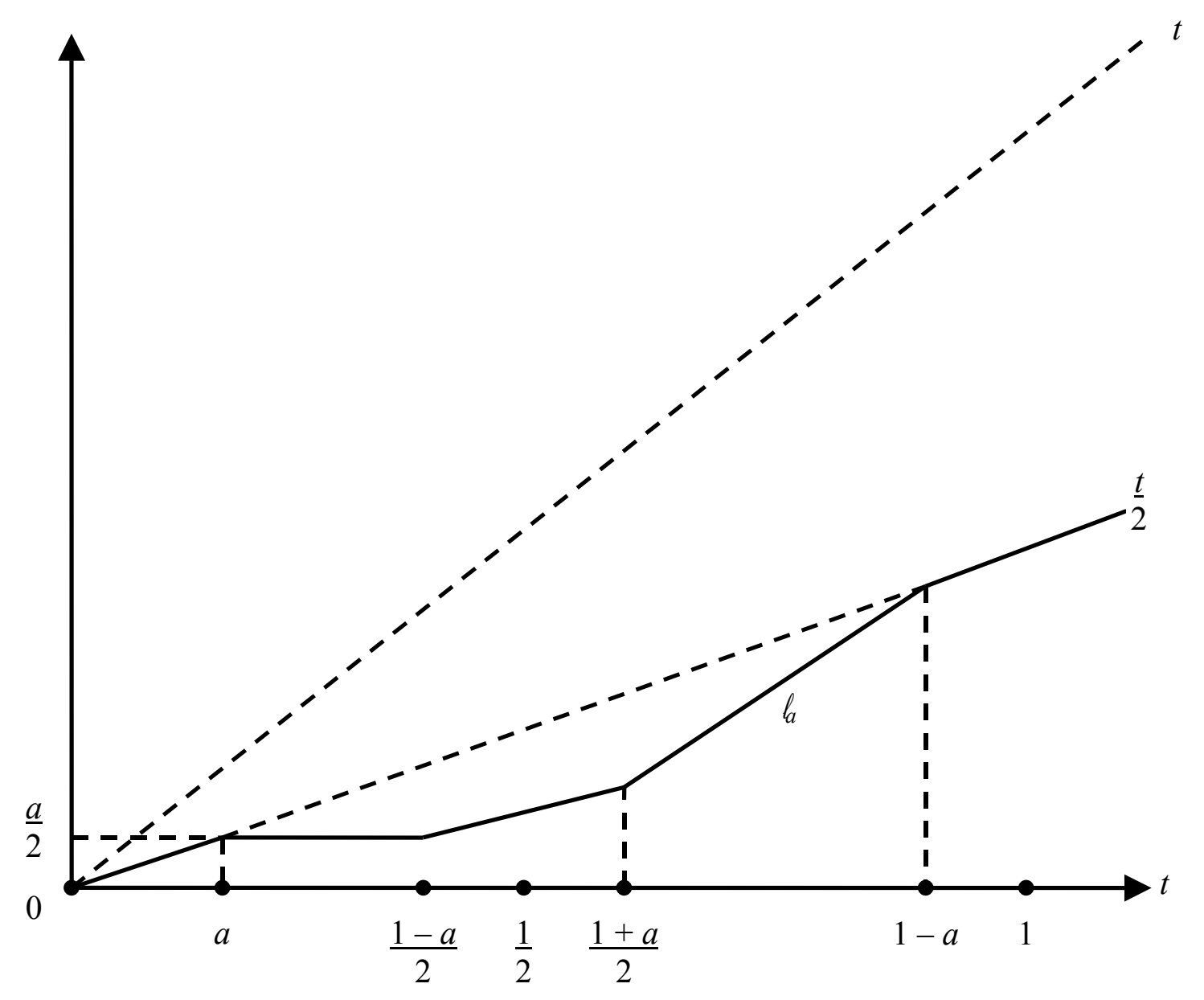

Figure 1: Graph of the Median $b_{a}$ 


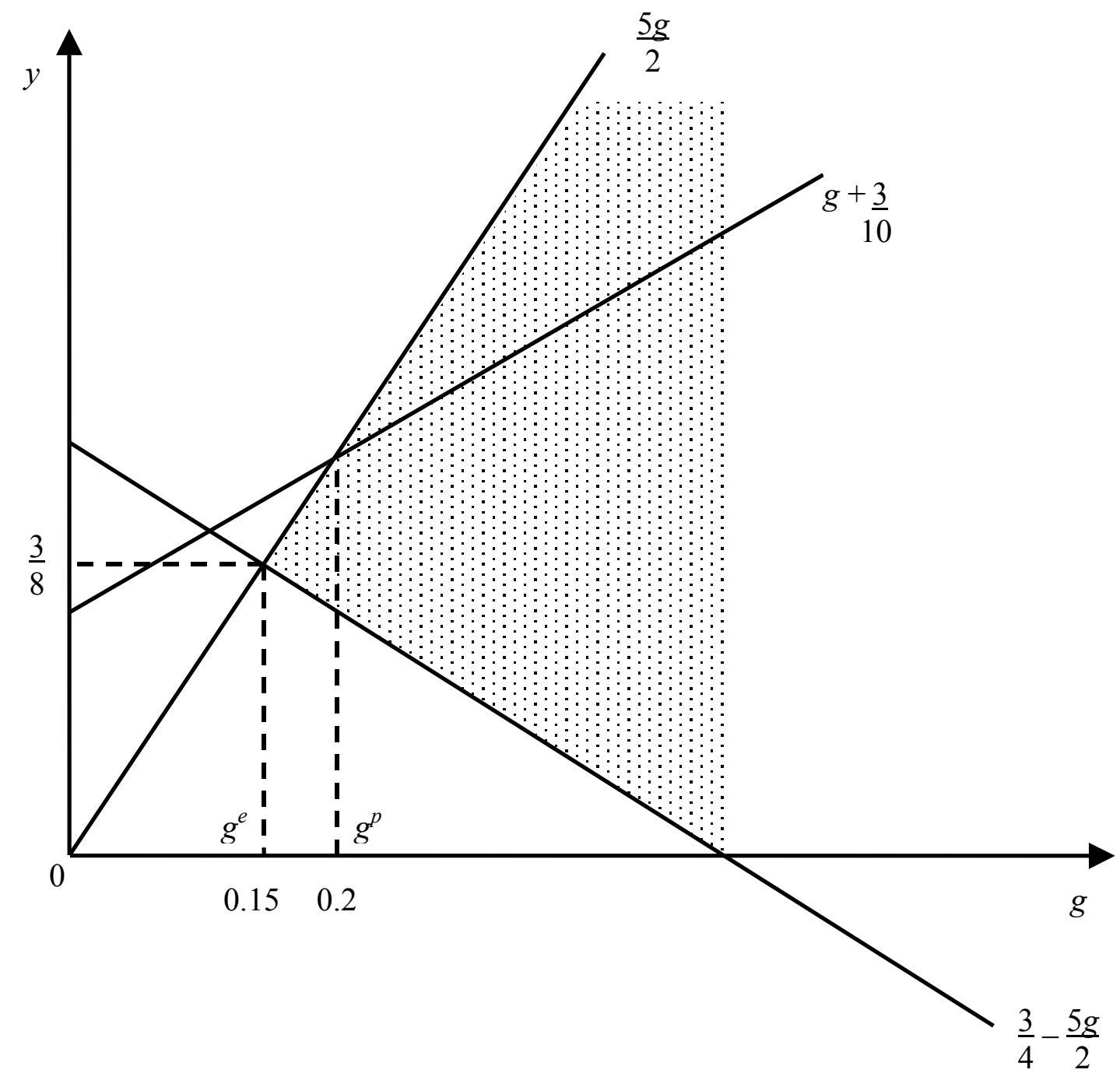

Figure 2: Secession Proof Transfers in Example 6.7 


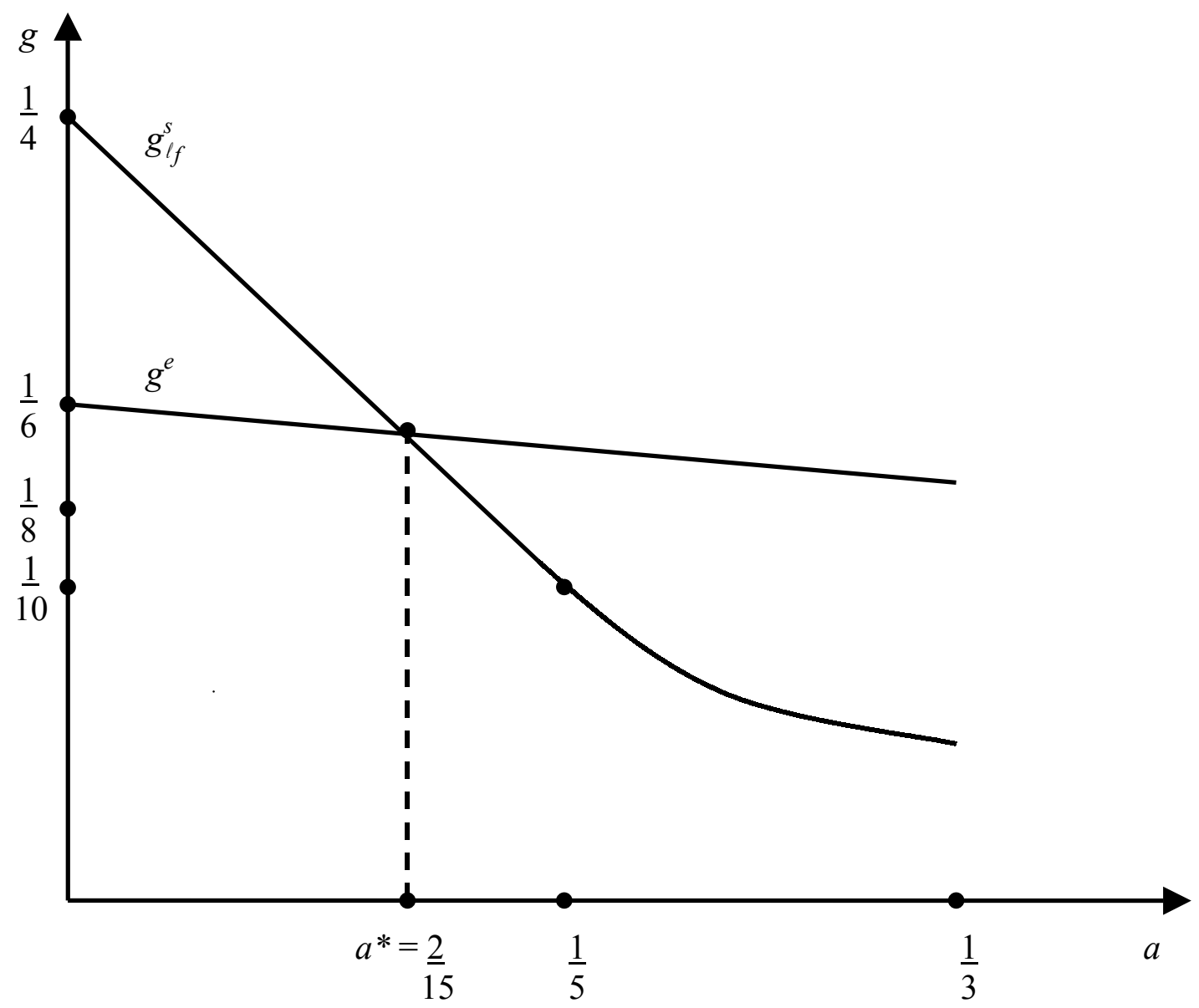

Figure 3: Graphs of $g^{e}$ and $g_{l_{f}}^{s}$ 